\title{
Promotion of mental health and prevention of mental disorders: priorities for implementation
}

M.M. Barry, A.M. Clarke' and I. Petersen ${ }^{2}$

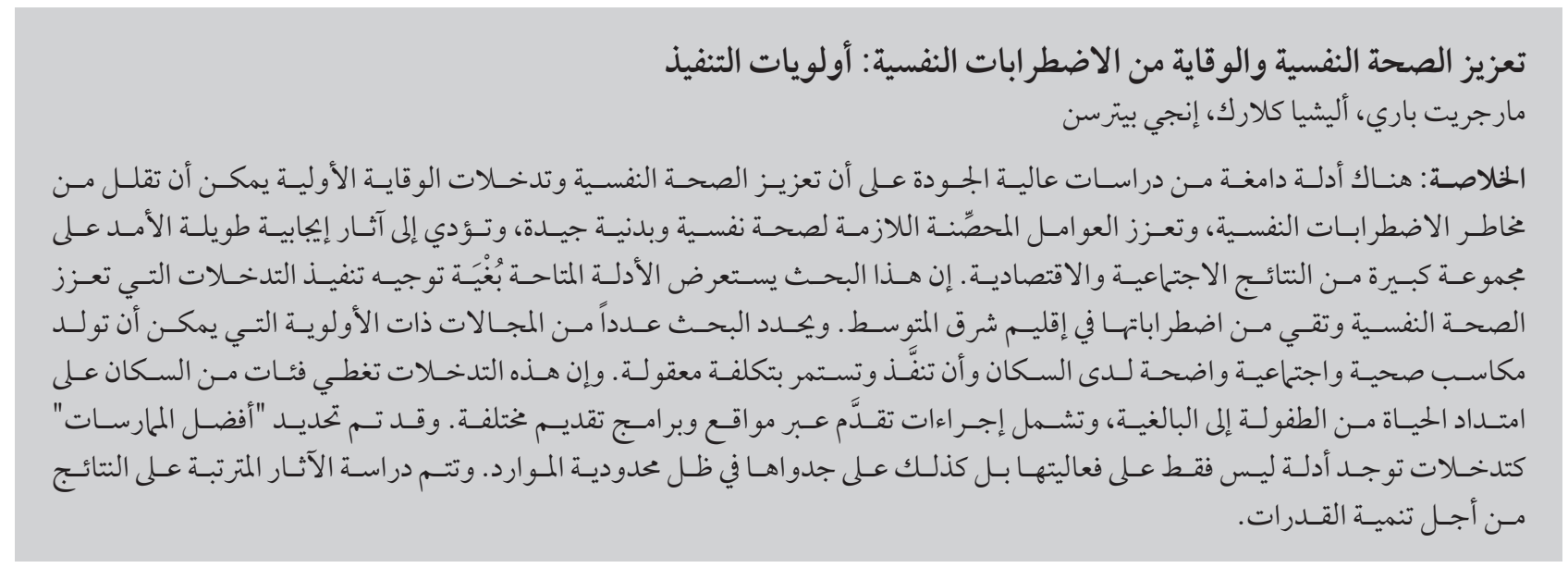

ABSTRACT There is compelling evidence from high-quality studies that mental health promotion and primary prevention interventions can reduce the risk of mental disorders, enhance protective factors for good mental and physical health, and lead to lasting positive effects on a range of social and economic outcomes. This paper reviews the available evidence in order to guide the implementation of mental health promotion and prevention interventions in the Eastern Mediterranean Region. The paper identifies a number of priority areas that can generate clear health and social gains in the population and be implemented and sustained at a reasonable cost. The interventions cover population groups across the lifespan from infancy to adulthood and include actions delivered across different settings and delivery platforms. "Best practices" were identified as interventions for which there is evidence not only of their effectiveness but also of their feasibility within resource constraints. The implications of the findings for capacity development are considered.

\section{Promotion de la santé mentale et prévention des troubles mentaux : priorités pour la mise en œuvre}

RÉSUMÉ Selon des preuves irréfutables issues d'études de haute qualité, la promotion de la santé mentale et les interventions de prévention primaire permettent de réduire le risque de troubles de santé mentale, de renforcer les facteurs protecteurs pour une bonne santé mentale et physique et de produire des effets positifs durables sur un éventail de problèmes socioéconomiques. Le présent article examine les preuves disponibles afin d'orienter la mise en œuvre d'interventions pour la promotion et la prévention de la santé mentale dans la Région de la Méditerranée orientale. Il identifie un certain nombre de domaines prioritaires qui peuvent générer de nettes améliorations sanitaires et sociales dans la population et être mis en œuvre puis pérennisés pour un coût raisonnable. Les interventions couvrent des groupes de population de tout âge, de la petite enfance à l'âge adulte et comprennent des actions menées dans des milieux variés et à partir de plateformes de prestation différentes. «Les meilleures pratiques » ont été identifiées comme étant des interventions pour lesquelles non seulement l'efficacité, mais aussi la faisabilité ont été prouvées dans un contexte de compression des ressources. Les implications des résultats en matière de renforcement des capacités sont en cours d'étude. 


\section{Introduction}

The World Health Organization's (WHO) comprehensive mental health action plan (2013-20) clearly identifies that good mental health is an integral component of population health and well-being and contributes to the functioning of individuals, families, communities and the social and economic prosperity of society $(1,2)$. There is a solid case for investing in mental health promotion and primary prevention, whether on the grounds of improving population health and well-being, reducing social and health inequities, protecting human rights or improving economic efficiency and development (1-3). Despite the growing recognition of the importance of good mental health, it remains a neglected aspect of public health in many countries. The WHO regional strategy on mental health and substance abuse in the Eastern Mediterranean Region (EMR) incorporates a clear focus on the implementation of evidence-based mental health promotion and prevention as one of its six strategic components (3). This includes developing strategies for mental health promotion and prevention in mental health, public health and other public policies requiring high-level collaboration across government departments and sectors.

Strategies focused on curing mental ill health alone will not necessarily deliver improved mental health at a population level (1). Mental health promotion and prevention strategies have been introduced in many countries globally as the most sustainable method of reducing the increasing burden of mental disorders and improving overall health and wellbeing. There is compelling evidence from high-quality studies that mental health promotion and prevention interventions, when implemented effectively, can reduce risk factors for mental disorders, enhance protective factors for good mental and physical health and lead to lasting positive effects on a range of social and economic outcomes (4-10). Mental health promotion and prevention needs to be integrated into population health improvement and development strategies, together with primary and secondary health care delivery.

This paper provides a briefing for policy-and decision-makers in the EMR on the evidence for mental health promotion and primary prevention interventions, identifying priority areas for action based on their effectiveness and feasibility of implementation. The international evidence from across high-, middle- and low-income countries shows that there are effective and feasible interventions for promoting mental health and preventing mental ill health that represent a costeffective use of resources and a strong case for policy investment. This paper provides a guide, based on best available evidence, to support decision-making in identifying priority areas and best practice for implementation.

\section{Frameworks for action}

Mental health promotion is concerned with promoting positive mental health and employs intersectoral strategies for strengthening protective factors and enabling access to resources and supportive environments that will keep individuals and populations mentally healthy $(4,7)$. Prevention aims to reduce the incidence, prevalence or seriousness of specific mental health problems, such as anxiety and depression (11). Primary prevention can be universal or it can target populations at risk (selective and indicated) and is distinguished from secondary prevention that focuses on early detection and treatment, and tertiary prevention that aims to reduce disability and enhance rehabilitation of people with mental disorders. Current frameworks for mental health promotion and prevention seek to intervene at different levels, by strengthening individuals, strengthening communities, reorienting health services and promoting intersectoral actions to remove structural barriers to mental health at a societal level $(4,5,7)$.

\section{Assessing best evidence}

The evidence for effectiveness of interventions was taken from existing databases, systematic reviews and meta-analyses in high-income countries and in low- and middle-income countries (LMICs). This paper draws particularly on a review of the evidence of mental health promotion interventions in LMICs completed for the WHO Task Force on Mainstreaming Health Promotion (10), a systematic review on interventions for young people in LMICs (8), meta-analyses of interventions to reduce stigma $(12,13)$, a review paper on mental health literacy (14) and a review of population and community level mental health promotion and prevention interventions (15).

In selecting priority interventions based on available evidence, so-called "best practices" are understood to be interventions for which there is not only evidence of their effectiveness but also of their feasibility in relation to their cultural acceptability as well as the capacity of existing service delivery systems to deliver the intervention to the intended target population within existing resource constraints (16). "Good practices" are interventions that do not meet all these criteria but are recommended based on the best available evidence. Given the paucity of cost-effectiveness studies on mental health promotion and prevention research in the Region, we recommend a set of best practices based on cost-effective evidence from high-income countries and evidence of feasibility in LMICs. Feasibility was determined on the basis of whether a task-sharing approach ${ }^{1}$ was

\footnotetext{
Task-sharing refers to "the redistribution of tasks to less specialized cadres or cadres with tailored training to perform a specific task under the supervision and support of specialists" (64).
} 
successfully adopted by a number of randomized control trials, given the limited evidence of interventions that have been scaled up more broadly in LMICs. A technical paper which gives full details of the research evidence supporting this briefing document is also available for consultation (17).

\section{Implementing mental health promotion and prevention strategies: priorities for action}

Priority areas for implementation are identified based on the available evidence on mental health promotion and primary prevention interventions from high-, middle- and low-income countries in terms of their ability to improve mental health and lead to social and economic benefits, and the feasibility of their implementation. The interventions cover population groups across the lifespan from infancy to adulthood, and include actions that can be delivered across different settings and delivery platforms.

Promote infant (aged 0-3 years) and maternal mental health (best practice)

Integrating mental health promotion and prevention interventions, such as parenting interventions to promote mother-child interaction, into routine pre- and postnatal care services, including home-visit parenting programmes, leads to improved parenting and child development, improved maternal health and social functioning and reduced behavioural problems in children $(18,19)$. Antenatal screening and targeted prevention interventions improve detection and management of postnatal depression for women at risk of depression and intimate partner violence $(20,21)$. The effects of early years interventions are especially evident for the most vulnerable families, including those living in poverty and war-torn areas, and for mothers with depression (22-25). Studies also show the sustained added value of combining psychosocial stimulation with nutritional supplements for extremely disadvantaged children who have stunted growth (24). Economic analyses of several early childhood interventions show that they can repay their investment with savings to government and benefits to society, with those at risk making the most gains $(6,21)$. Home-visiting interventions which integrate the promotion of mental health have demonstrated longterm positive outcomes for mothers and babies, have the potential to be scaled up in LMICs and are recommended as a best practice.

Promote early child mental health development (aged 3-6 years) through preschool education/enrichment programmes (good practice)

High quality early childhood enrichment programmes result in enduring gains in children's social and emotional well-being, cognitive skills, problem behaviours and readiness for school $(19,26,27)$. Long-term effects on school attainment, social gains and occupational status have been found, with greater benefits for higher risk and more disadvantaged children $(28,29)$. Pre-school programmes indicate a benefit-to-cost ratio as high as 17.6 to 1 (28), with favourable benefit-cost ratios being reported for even the most intensive programmes. Examples of successful implementation in LMIC contexts include the development of a preschool programme for families of low education in Bangladesh (30) and the long-term impact of the Turkish Early Enrichment Project implemented by mothers with the help of local paraprofessionals (31). Due to the limited evidence on scaling up in LMICs, enrichment/preschool education integrating emotional and social skills development for children is recommended as a good practice.
Implement parenting and family strengthening programmes for schoolgoing children (aged 3-16 years) (good practice)

Universal and targeted parenting and family strengthening interventions promote child emotional and behavioural adjustment, particularly in younger children (aged 3-10 years) and can prevent conduct disorder in at-risk families (32-34). The benefits of targeted parenting programmes for the prevention of persistent conduct disorders outweigh the costs around 8 to 1 in high-income countries (6), with benefits accruing mainly in the criminal justice system. In view of limited evidence from LMICs, parenting/ family strengthening interventions for school-going children are suggested as a good practice, with the recommendation that studies in the EMR be conducted to demonstrate their effectiveness and feasibility.

Promote young people's (aged 6-18 years) life skills and resilience through whole school-based interventions in primary and post-primary schools (best practice)

Universal (for all children) social and emotional learning interventions in primary and post-primary schools lead to long-term benefits in children's social and emotional functioning and academic performance $(35,36)$. Interventions employing a wholeschool approach (involving staff, students, parents, the school environment and the local community) are more effective than curriculum-only programmes, including addressing problems such as bullying (37). School-based interventions which enhance coping skills, resilience and cognitive skills for children at higher risk are effective in preventing anxiety and depression and have been adapted successfully in LMIC settings $(8,38)$.

These interventions can be feasibly delivered by teachers in low-resource settings, and economic analyses show 
that social and emotional learning interventions are cost-saving in terms of the positive impact on crime and health outcomes (6). Universal and targeted school interventions are recommended as a best practice.

Implement selective class-room-based interventions for vulnerable children (orphaned by HIV or living in areas of conflict/war) (good practice)

The prevalence of mental disorders in children living in countries at war and with complex emergencies is extremely high. In the EMR, estimates of mental disorders in schoolchildren range from $22.2 \%$ in Afghanistan to $54.4 \%$ of boys in Palestine (3). Classroom-based interventions which aim to reduce distress and enhance resilience and coping skills have been found to improve psychological functioning and coping in some studies but not in others $(39,40)$. Positive effects seem to be moderated and mediated by personal attributes, including age and sex as well as the severity of risk and difficulties, and may be more suited to contexts where the risks and difficulties are less severe (41).

Promote the mental health and social well-being of adolescents and young people (aged 12-18+ years) through out-of-school multicomponent interventions (good practice)

Out-of-school youth empowerment programmes improve the mental health of young people in LMICs through promoting life skills, greater gender equity, reduced intimate personal violence and poverty reduction, thus addressing some of the social determinants of mental health. Multicomponent, community-based interventions that address emotional and sexual health, HIV prevention, substance misuse, violence prevention and literacy and social functioning among vulnerable youth show the potential for scaling up initiatives (8). The implementation of youth empowerment programmes is recommended as a good practice based on evidence from the Ishraq intervention in Egypt, which provides an example of a promising intervention from the EMR delivered using a task-sharing approach (42).

\section{Facilitate community empowerment} interventions to promote mental health and reduce the risk of mental disorders for families in poverty and debt (good practice)

Poverty and debt impact negatively on mental health; people experiencing unmanageable debt have been shown to be at higher risk of mental disorders and suicide. Combined community microfinance and health training interventions have positive mental health and social benefits, including improved well-being and psychological health, improved nutrition, higher educational attainment, reduced risk of violence and improved social participation, empowerment and economic well-being (43). Microcredit schemes, which combine microfinance and training interventions that promote essential life skills, asset building and resourcefulness, are more effective in terms of mental health benefits (44). There is encouraging evidence from initiatives such as the IMAGE intervention in South Africa, which combines training on gender issues and HIV with microfinance initiatives for women $(45,46)$, and an economic empowerment initiative for AIDS orphaned children, which has also shown positive impacts on participants' selfesteem and reduced levels of depression (47). Microfinance interventions for young adults and women, which are cost-effective from both a societal and public health perspective, are recommended as a good practice.

Train primary health care providers in opportunistic mental health promotion and prevention interventions for adults and older people (good practice)

Many adults and older people with mental health problems in the EMR first seek care from primary health-care practitioners (3). The training of primary health-care providers in screening and brief interventions for alcohol misuse can reduce harmful alcohol use, and training in the identification and management of mental disorders can prevent suicide (48). Briefinterventions by primary health-care practitioners on alcohol consumption is considered more cost-effective than policy-level interventions (see the section on policy/ regulations) in countries where the rate of harmful drinking is low and risky drinking is not widespread (49). Brief, passive psychoeducational interventions for individuals with depression and psychological distress should also be considered, given evidence from high-income countries that these interventions can reduce symptoms (50).

\section{Advocate for workplace policies \& programmes that will improve the mental health of working adults (good practice)}

Integrating mental health into workplace health and safety regulations, including workers' rights, job security, increased job control and autonomy and anti-bullying measures, will improve and maintain good mental health at work, with the gain from comprehensive approaches being reflected in reduced absenteeism, improved well-being and improved productivity $(6,51-53)$.

The new SOLVE training package, developed by the International Labour Organization, is designed to reduce the incidence of work-related stress, workplace violence (physical and psychological), tobacco, alcohol and drug misuse and HIV/AIDS. This intervention, which has been implemented in several LMICs (53), is recommended for implementation supported by more rigorous research on its impact in the EMR.

Implement suicide prevention programmes (good practice)

While suicide rates in the EMR countries are generally lower compared with other WHO regions (54), relatively high suicide rates have been observed among young women and men aged 
15-29 years in LMICs in the EMR (8.6 and 7.6 per 100000 respectively) and women and men aged 60 years and older (7.0 and 10.8 per 100000 respectively) (54). The "criminalization" of suicidal behaviour in such countries may explain to some extent why reported suicide mortality rates are lower in the EMR than in other regions $(55,56)$.

There is growing evidence to support the implementation of a broad range of interventions to reduce and prevent suicide and self-harm in different settings and cultural contexts. Some of the interventions that have been found to be effective include: responsible media reporting, restricting access to the means of suicide, training of health personnel for early recognition and management of priority mental, neurological and substance use disorders (57,58), and school-based skills training and social support for at-risk students (58). However, further evaluation together with modifications to the context of EMR countries is needed. Setting up systems to capture information about the rates of suicides and suicide attempts, the methods of suicide employed and the demographic characteristics of victims, as well as action towards decriminalization of suicide, could be the first step for countries of the Region towards suicide prevention. Regulations restricting access to commonly used lethal means of suicide (region-specific) is also a cost-effective means to reduce suicide rates (52).

Promote mental health literacy and reduction of stigma through multicomponent public awareness campaigns and community-based educational training interventions (good practice)

Mental health literacy is defined as "knowledge and beliefs about mental disorders which aid their recognition, management or prevention" (14). Stigma towards people with mental disorders is multifaceted, comprising ignorance (lack of knowledge), prejudice (stigmatizing attitudes) and discrimination (being treated unfairly) (59).
Drawing on recent systematic reviews, meta-analyses of stigma interventions $(12,13)$ and a review paper on mental health literacy (14), the following interventions for promoting mental health literacy and reducing stigma can be identified: mass promotion through the media, setting up of dedicated websites, school education programmes, and mental health first aid training. The evidence for their effectiveness comes primarily from high-income countries. Therefore, at this point the decision to scale up these interventions in LMICs has to be taken based on the context of individual countries. Furthermore, there have been no studies on the costeffectiveness of such interventions.

- Mass mental health literacy promotion programmes can improve the general public's knowledge of mental disorders and to some extent improve the public's acceptance and reduce their prejudice towards people with mental health problems. However, these can be costly to implement and their broader impacts are not known (60).

- Internet interventions are at least as effective as face-to-face interventions at reducing the stigma of mental health (13). They have the capacity to reach large numbers of people, even in low-income countries. Adapting existing websites designed for highincome countries could be relatively inexpensive to implement for low-income countries.

- Mentalhealtheducation programmes in schools can improve mental health knowledge of children (61). While most studies of school programmes have been carried out in high-income countries, one of the best evaluated in a low-income country was carried out in rural Pakistan. This demonstrated improved knowledge not only in students, but also in adults in the broader community (62).

- There are a number of programmes that train members of the public to assist people who are at risk of developing a mental health problem or who are suicidal or in crisis. Mental health first aid training is the best-researched intervention and has been found to change people's knowledge, attitudes and behaviour towards mental ill health (63). This type of training is being implemented in a number of low- and middleincome countries, including two Eastern Mediterranean countries (Saudi Arabia and Pakistan).

\section{Discussion}

This review has identified a number of priority areas and best practices for implementation in promoting mental health and preventing mental ill health across the lifespan and different settings and delivery platforms. Based on available research from high-, middle- and low-income countries, there is convincing evidence of the effectiveness of interventions that could feasibly be implemented in the EMR. The limitations of this review must be acknowledged in terms of the bias towards English language publications and the possibility that studies published in other languages may not have been accessed. In addition, studies not employing experimental designs were not included and, therefore, some potentially promising interventions may have been excluded in the search process. The paucity of cost-effectiveness studies from countries within the Region is a clear limitation. However, the interventions identified are based on well-designed research studies and clearly demonstrate what can be achieved when the necessary resources, expertise and capacity are made available. The review findings support the recommendation of a number of priority interventions, as outlined in Box 1.

Developing the capacity for implementing the priority areas and best practices identified in this review is a critical next step in promoting population mental health in the Region. This includes 
promoting a better understanding among policy-makers, health professionals and the public more generally of the need for mental health promotion and prevention interventions and how these contribute to achieving the goals of population health, social and economic well-being and the broader development agenda at a country level. Treatment approaches alone will not be sufficient to meet the challenge of the growing burden of mental disorders and it is critical that countries invest in early intervention, prevention and promotion of good mental health at a population level.

\section{Implications for policy and practice}

At a policy level, there is a need for strategic investment in developing and supporting national leadership, technical expertise and workforce development for mental health promotion and prevention in the EMR. Collectively, the evidence in this review points to the potential of scaling-up intervention approaches that can be sustained at a reasonable cost through the use of trained paraprofessionals and preexisting structures and resources working collaboratively on a cross-sectoral basis. Workforce capacity for mental health promotion and prevention needs to be developed across the health, education, community and related sectors, with a focus on harnessing available skills and resources for the implementation of evidence-informed best practices. Planning and implementation groups will need to be established in order to design and facilitate action at a regional, country and district level. Local expertise will be required in contextualizing policies and translating international evidence into effective actions tailored to the cultural and socioeconomic contexts of countries in the Region. The provision of training and skill development in the implementation of promotion and prevention approaches will be needed in order to support the delivery of best practices by local professionals and community workers. The development of workforce competencies in promotion and prevention work will need to be given greater priority in public health and mental health services at both regional and country level to ensure that the necessary commitment and expertise will be mobilized effectively.

\section{Implications for research}

The best practice interventions identified in this review have achieved success across a diverse range of countries and contexts. However, few have been scaled up at a country level. Therefore, evidence of the feasibility of implementing these in an effective and sustainable manner in the EMR needs to be strengthened. Further research is needed to demonstrate the cost-effectiveness of the best practices as applied in the regional context. As there are a

Box 1 Recommended priority actions for promotion of mental health and prevention of mental disorders in the Eastern Mediterranean Region

- Promote infant (aged 0-3 years) and maternal mental health through integrating mental health promotion and prevention into routine pre- and postnatal care services and home visiting programmes.

- $\quad$ Promote early child mental health development (aged 3-6 years) through preschool education/enrichment programmes.

- Implement parenting and family strengthening programmes for school-going children (aged 3-16 years).

- Promote young people's (6-18 years) life skills and resilience through whole school-based interventions in primary and post-primary schools.

- Implement selective classroom-based interventions for vulnerable children (orphaned by HIV or living in areas of conflict/war).

- $\quad$ Promote the mental health and social well-being of adolescents and young people (aged 12-18+ years) through out-of-school multicomponent interventions.

- Facilitate community empowerment interventions to promote mental health and reduce the risk of mental disorders for families in poverty and debt.

- Train primary health-care providers in opportunistic mental health promotion and prevention interventions for adults and older people.

- Advocate for workplace policies and programmes that will improve the mental health of working adults.

- Implement suicide prevention programmes, including regulations on restricting access to commonly used lethal means of suicide, decriminalize suicide and establish improved reporting systems.

- Promote mental health literacy and reduction of stigma through multi-component public awareness campaigns and community-based educational training interventions. 
limited number of studies providing robust evidence in certain action areas, it will also be important to determine how well-validated interventions developed in high-income countries could be adapted and implemented in the Region. Implementation research is needed to examine the level and quality of planning, delivery and resourcing required to ensure successful adaptation and transferability of interventions across diverse cultural and socioeconomic settings. The development of culturally valid measures of mental health that will support the evaluation of culturally appropriate interventions in the Region is identified as an area for methodological development that will be critical to the advancement of work in this area. Strengthening local research capacity will be an important aspect of supporting and advancing the development and evaluation of mental health promotion and prevention interventions in the regional context.

\section{Conclusions}

There is an urgent need to investin building the policy, practice and research capacity for mental health promotion and prevention in the EMR to ensure that resources are in place for implementing and evaluating the interventions identified as best practices and good practices in the local context. Developing the regional evidence base on the implementation, outcomes and actual costs of the interventions described in this paper is an important next step, together with further work on the cultural adaptation and tailoring of implementation approaches to local needs and resources. Workforce capacity needs to be built for the integration of interventions into existing public health, mental health and development programmes and social policies in partnership with the health, social services, education, employment and community sectors. This will ensure a positive impact on population mental health, especially for the most vulnerable communities, together with wideranging health, social and economic benefits for society.

\section{Acknowledgements}

We acknowledge the contributions of Professor Anthony Jorm, Centre for Mental Health, University of Melbourne, Australia and Professor Ella Arensman of the Irish National Suicide Research Foundation for their input in the areas of mental health literacy and suicide prevention respectively.

\section{References}

1. Mental Health Action Plan 2013-2020. Geneva: World Health Organization; 2013.

2. Investing in mental health evidence for action. Geneva: World Health Organization; 2013.

3. Regional Strategy on Mental Health and Substance Abuse. Cairo: World Health Organization; 2012 (WHO-EMMNH191E) (http://apps.who.int/iris/bitstream/10665/116830/1/EMROPUB_2012_EN_1067.pdf?ua=1, accessed 9 February 2015).

4. Herrman H, Saxena S, Moodie R. Promoting mental health: concepts, emerging evidence, practice. Summary report. A report of the World Health Organization, Department of Mental Health and Substance Abuse in collaboration with the Victorian Health Promotion Foundation and University of Melbourne. Geneva: World Health Organization; 2005 (http:// www.who.int/mental_health/evidence/en/promoting_mhh. pdf, accessed 9 February 2015).

5. Saxena S, Jané-Llopis E, Hosman C. Prevention of mental and behavioural disorders: implications for policy and practice. World Psychiatry. 2006 Feb;5(1):5-14. PMID:16757984

6. Knapp M, McDaid D, Parsonage M. Mental health promotion and prevention: the economic case. London: London School of Economics and Political Science, Personal Social Services Research Unit; 2011.

7. Barry MM, Jenkins R. Implementing mental health promotion. Oxford: Churchill Livingstone Elsevier; 2007.

8. Barry MM, Clarke AM, Jenkins R, Patel V. The effectiveness of mental health promotion interventions for young people in low and middle income countries: A systematic review. BMC Public Health. 2013;13:835. PMID:24025155

9. Jané-Llopis E, Barry MM, Hosman C, Patel V. Mental health promotion works: a review. In: Jané-Llopis E, Barry MM, Hosman C, Patel V, editors. The evidence of mental health promotion effectiveness: strategies for action. Promotion and Education Supplement. 2005;2:9-25

10. Barry MM, Clarke AM, Jenkins R, Patel V. Rapid review of the evidence on the effectiveness of mental health promotion interventions in low and middle income countries. Mainstreaming health promotion: reviewing the health promotion actions for priority public health conditions. Geneva: World Health Organization; 2011.

11. Mrazek PJ, Haggerty RJ. Reducing risks for mental disorders: frontiers for preventive intervention research. Washington (DC): National Academy Press; 1994.

12. Corrigan PW, Morris SB, Michaels PJ, Rafacz JD, Rüsch N. Challenging the public stigma of mental illness: a meta-analysis of outcome studies. Psychiatr Serv. 2012 Oct;63(10):963-73. PMID:23032675

13. Griffiths KM, Carron-Arthur B, Parsons A, Reid R. Effectiveness of programs for reducing the stigma associated with mental disorders. A meta-analysis of randomized controlled trials. World Psychiatry. 2014 Jun;13(2):161-75. PMID:24890069

14. Jorm AF. Mental health literacy: empowering the community to take action for better mental health. Am Psychol. 2012 Apr;67(3):231-43. PMID:22040221

15. Petersen I, Evans Lacko S, Semrau M, Barry MM, Gronholm, P, Chisholm D, et al. Population and community level interventions: Disease Control Priorities for Mental Neurological and Substance-Use Disorders. In: Patel V, Chisholm D, Dua T, Laxminarayan R, Medina-Mora ME, editors. Disease control priorities, 3rd edition. Washington (DC): World Bank (forthcoming).

16. Carter R, Stone C, Vos T, Hocking J, Mihalopoulos C, Peacock $S$, et al. Trial of Program Budgeting and Marginal Analysis (PBMA) to Assist Cancer Control Planning in Australia. Can- 
berra: Commonwealth Department of Health and Aged Care; 2000.

17. Barry M, Clarke AM, Petersen I. Priorities for implementing the promotion of mental health and primary prevention of mental disorders. Technical report prepared for the WHO InterCountry Meeting on Implementation of Global Mental Health Action Plan in the Eastern Mediterranean Region. Cairo: World Health Organization Regional Office for the Eastern Mediterranean; 2014.

18. Kendrick D, Elkan R, Hewitt M, Dewey M, Blair M, Robinson J, et al. Does home visiting improve parenting and the quality of the home environment? A systematic review and meta analysis. Arch Dis Child. 2000 Jun;82(6):443-51. PMID:10833174

19. Tennant R, Goens C, Barlow J, Day C, Stewart-Brown S. A systematic review of reviews of interventions to promote mental health and prevent mental health problems in children and young people. Journal of Public Mental Health. 2007;6(1):2532.

20. Antenatal and postnatal mental health. Clinical management and service guidance. London: National Institute for Health and Clinical Excellence; 2007 (NICE Clinical Guideline 45).

21. Shaw E, Levitt C, Wong S, Kaczorowski J; McMaster University Postpartum Research Group. Systematic review of the literature on postpartum care: effectiveness of postpartum support to improve maternal parenting, mental health, quality of life, and physical health. Birth. 2006 Sep;33(3):210-20. PMID:16948721

22. Baker-Henningham H, Lopez Boo F. Early childhood stimulation interventions in developing countries: a comprehensive literature review. Washington (DC): Banco Interamericano de Desarrollo, Social Protection and Health Division; 2010.

23. Nores M, Barnett WS. Benefits of early childhood interventions across the world: (Under) Investing in the very young. Econ Educ Rev. 2010;29(2):271-82.

24. Walker SP, Chang SM, Powell CA, Simonoff E, GranthamMcGregor SM. Effects of psychosocial stimulation and dietary supplementation in early childhood on psychosocial functioning in late adolescence: follow-up of randomised controlled trial. BMJ. 2006 Sep 2;333(7566):472-4. PMID:16877454

25. Rahman A, Malik A, Sikander S, Roberts C, Creed F. Cognitive behaviour therapy-based intervention by community health workers for mothers with depression and their infants in rural Pakistan: a cluster-randomised controlled trial. Lancet. 2008 Sep 13;372(9642):902-9. PMID:18790313

26. Anderson LM, Shinn C, Fullilove MT, Scrimshaw SC, Fielding JE, Normand J, et al.; Task Force on Community Preventive Services. The effectiveness of early childhood development programs. A systematic review. Am J Prev Med. 2003 Apr;24(3) Suppl:32-46. PMID:12668197

27. Nelson G, Westhues A, MacLeod J. A meta-analysis of longitudinal research on preschool prevention programs for children. Prev Treat. 2003;6(31)

28. Schweinhart LJ, Montie J, Xiang Z, Barnett WS, Belfield CR, Nores M. Lifetime effects: The HighScope Perry pre-school study through age 40. Ypsilanti (MI): HighScope Press; 2005 (Monographs of the HighScope Educational Research Foundation 14).

29. Engle PL, Fernald LCH, Alderman H, Behrman J, O'Gara C, Yousafzai A, et al.; Global Child Development Steering Group. Strategies for reducing inequalities and improving developmental outcomes for young children in low-income and middle-income countries. Lancet. 2011 Oct 8;378(9799):1339-53. PMID:21944378

30. Aboud FE. Evaluation of an early childhood preschool program in rural Bangladesh. Early Child Res Q. 2006;21(1):46-60.

31. Kagitcibasi C, Sunar D, Bekman S, Baydar N, Cemalcilar Z. Continuing effects of early enrichment in adult life: The Turk- ish Early Enrichment Project 22 years later. J Appl Dev Psychol. 2009;30(6):764-79.

32. Barlow J, Parsons J, Stewart-Brown S. Preventing emotional and behavioural problems: the effectiveness of parenting programmes with children less than 3 years of age. Child Care Health Dev. 2005 Jan;31(1):33-42. PMID:15658964

33. NICE. Parent training education programmes in the management for children with conduct disorders. London: National Institute for Health and Clinical Excellence; 2006 (Technology Appraisal Guidance 102).

34. Dretzke J, Davenport C, Frew E, Barlow J, Stewart-Brown S, Bayliss S, et al. The clinical effectiveness of different parenting programmes for children with conduct problems: a systematic review of randomised controlled trials. Child Adolesc Psychiatry Ment Health. 2009;3(1):7. PMID:19261188

35. Durlak JA, Weissberg RP, Dymnicki AB, Taylor RD, Schellinger KB. The impact of enhancing students' social and emotional learning: a meta-analysis of school-based universal interventions. Child Dev. 2011 Jan-Feb;82(1):405-32. PMID:21291449

36. Weare K, Nind M. Mental health promotion and problem prevention in schools: what does the evidence say? Health Promot Int. 2011 Dec;26 Suppl 1:i29-69. PMID:22079935

37. Olweus D, Limber S, Mihalic S. Blueprints for violence prevention. Book nine: Bullying Prevention Program. Boulder (CO): Center for the Study and Prevention of Violence, Institute of Behavioral Science; 1998.

38. Caldwell LL, Smith EA, Collins LM, Graham JW, Lai M, Wegner L, et al. Translational Research in South Africa: Evaluating Implementation Quality Using a Factorial Design. Child Youth Care Forum. 2012 Apr 1;41(2):119-36. PMID:22707870

39. Jordans MJD, Tol WA, Komproe IH, De Jong JVTM. Systematic review of evidence and treatment approaches: Psychosocial and mental health care for children in war. Child Adolesc Ment Health. 2009;14(1):2-14.

40. Khamis $\mathrm{V}$, Macy $\mathrm{R}$, Coignez $\mathrm{V}$. The impact of the classroom community camp-based intervention $\left(\mathrm{CBI}^{*}\right)$ program on Palestinian children. Jerusalem: Save the Children USA West Bank/ Gaza Field Office; 2004 (http://pdf.usaid.gov/pdf_docs/ PNADJ085.pdf, accessed 9 February 2015).

41. Tol WA, Komproe IH, Jordans MJ, Ndayisaba A, Ntamutumba $P$, Sipsma H, et al. School-based mental health intervention for children in war-affected Burundi: a cluster randomized trial. BMC Med. 2014;12(1):56. PMID:24690470

42. Brady M, Assaad R, Ibrahim B, Salem A, Salem R. Providing new opportunities to adolescent girls in socially conservative settings: the Ishraq program in rural Upper Egypt. New York: Population Council; 2007.

43. Chowdhury A, Bhuiya A. Do poverty alleviation programmes reduce inequalities in health? The Bangladesh experience. In: Leon D, Walt G, editors. Poverty, inequality and health: an international perspective. Oxford: Oxford University Press; 2001. pp. 312-32.

44. Stewart R, Van Rooyen C, Dickson K, Majoro M, de Wet T. What is the impact of Microfinance on poor people? A systematic review of evidence from Sub-Saharan Africa. Technical report. London: EPPI Centre, Social Science Research Unit, University of London; 2010.

45. Kim JC, Watts CH, Hargreaves JR, Ndhlovu LX, Phetla G, Morison LA, et al. Understanding the impact of a microfinancebased intervention on women's empowerment and the reduction of intimate partner violence in South Africa. Am J Public Health. 2007 Oct;97(10):1794-802. PMID:17761566

46. Pronyk PM, Hargreaves JR, Kim JC, Morison LA, Phetla G, Watts $C$, et al. Effect of a structural intervention for the prevention of intimate-partner violence and HIV in rural South Africa: a clus- 
ter randomised trial. Lancet. 2006 Dec 2;368(9551):1973-83. PMID:17141704

47. Ssewamala FM, Han CK, Neilands TB. Asset ownership and health and mental health functioning among AIDS-orphaned adolescents: findings from a randomized clinical trial in rural Uganda. Soc Sci Med. 2009 Jul;69(2):191-8. PMID:19520472

48. van der Feltz-Cornelis CM, Sarchiapone M, Postuvan V, Volker D, Roskar S, Grum AT, et al. Best practice elements of multileve suicide prevention strategies: a review of systematic reviews. Crisis. 2011;32(6):319-33. PMID:21945840

49. Rehm J, Chisholm D, Room R, Lopez A. Alcohol. In: Jamison D, Breman J, Measham A, Alleyne G, Evans D, Jha P, et al., editors. Disease control priorities in developing countries. 2nd ed. New York: Oxford University Press; 2006. pp. 887-906.

50. Donker T, Griffiths KM, Cuijpers P, Christensen H. Psychoeducation for depression, anxiety and psychological distress: a meta-analysis. BMC Med. 2009;7:79. PMID:20015347

51. Mental health and work: impact, issues and good practices Geneva: World Health Organization and International Labour Organization; 2000.

52. Richardson KM, Rothstein HR. Effects of occupational stress management intervention programs: a meta-analysis. J Occup Health Psychol. 2008 Jan;13(1):69-93. PMID:18211170

53. Probst TM, Gold D, Caborn J. A preliminary evaluation of SOLVE: addressing psychosocial problems at work. J Occup Health Psychol. 2008 Jan;13(1):32-42. PMID:18211167

54. Rezaeian M. Suicidehomicide ratios in countries of the Eastern Mediterranean Region. East Mediterr Health J. 2008 NovDec;14(6):1459-65. PMID:19161122

55. Beautrais AL. Suicide in Asia. Crisis. 2006;27(2):55-7 PMID:16913325

56. Khan MM. Suicide prevention in Pakistan: an impossible challenge? J Pak Med Assoc. 2007 Oct;57(10):478-80. PMID:17990419
57. Preventing suicide: a global imperative. Geneva: World Health Organization; 2014 (http:apps.who.intirisbitstream1066513105619789241564779_eng.pdf accessed 23 November 2014)

58. Teuton D, Platt S, Atkinson A. Prevention of suicide and selfharm: Research briefing. 1st ed. Edinburgh: NHS Health Scotland; 2014.

59. Thornicroft G, Rose D, Kassam A, Sartorius N. Stigma: ignorance, prejudice or discrimination? Br J Psychiatry. 2007 Mar;190:192-3. PMID:17329736

60. Dumesnil H, Verger P. Public awareness campaigns about depression and suicide: a review. Psychiatr Serv. 2009 Sep;60(9):1203-13. PMID:19723735

61. Wei Y, Hayden JA, Kutcher S, Zygmunt A, McGrath P. The effectiveness of school mental health literacy programs to address knowledge, attitudes and help seeking among youth. Early Interv Psychiatry. 2013 May;7(2):109-21. PMID:23343220

62. Rahman A, Mubbashar MH, Gater R, Goldberg D. Randomised trial of impact of school mental-health programme in rural Rawalpindi, Pakistan. Lancet. 1998 Sep 26;352(9133):1022-5. PMID:9759745

63. Hadlaczky G, Hökby S, Mkrtchian A, Carli V, Wasserman D. Mental Health First Aid is an effective public health intervention for improving knowledge, attitudes, and behaviour: a meta-analysis. Int Rev Psychiatry. 2014 Aug;26(4):467-75. PMID:25137113

64. Mutamba BB, van Ginneken N, Smith Paintain L, Wandiembe S, Schellenberg D. Roles and effectiveness of lay community health workers in the prevention of mental, neurological and substance use disorders in low and middle income countries: a systematic review. BMC Health Serv Res. 2013;13:412. PMID:24119375 